\title{
Violências Intrafamiliares Experienciadas na Infância em Homens Autores de Violência Conjugal
}

\author{
Priscila Jandrey Brasco ${ }^{1}$ \\ ${ }^{1}$ Universidade Federal de Ciências da Saúde de Porto \\ Alegre, RS, Brasil.
}

\author{
Clarissa De Antoni ${ }^{1}$ \\ ${ }^{1}$ Universidade Federal de Ciências da Saúde de Porto \\ Alegre, RS, Brasil.
}

\begin{abstract}
Resumo: O objetivo do presente estudo foi conhecer como se constituíram as vivências na família de origem de homens envolvidos em relações conjugais violentas. Trata-se de pesquisa qualitativa exploratória. Foram entrevistados nove homens autores de violência doméstica, respondendo a processos judiciais com base na Lei ${ }^{\circ}$ 11.340/2006 (Lei Maria da Penha). Utilizou-se análise temática como método de análise de dados, sendo abordados três temas neste trabalho: negligência afetiva, exposição à violência física na infância e figura masculina de referência. Os resultados foram analisados sob a perspectiva da Teoria Bioecológica do Desenvolvimento Humano. Conclui-se que a construção das masculinidades desses homens sofreu influência de suas vivências anteriores, pautadas por modelos parentais severos, abusivos e negligentes. A figura de referência masculina também é vista como ausente e rígida, exercendo controle sobre o microssistema familiar. Essas experiências podem revelar a construção de um modelo no qual o homem acredita que seu papel também deva ser desempenhado por controle e domínio baseados na violência. Desta forma, isso pode ser considerado um fator de risco para o envolvimento em relações conjugais violentas, já que revela a fragilidade na construção do vínculo de confiança e reverbera nos relacionamentos vividos durante a vida adulta. É importante que esses homens tenham espaços de reflexão sobre suas ações em âmbito conjugal, a fim de ressignificar as experiências de abuso sofridas na infância.
\end{abstract}

Palavras-chave: Maus-tratos Infantis, Violência Doméstica, Parentalidade, Masculinidade.

\section{Intrafamily Violence Experienced in Childhood of Men Authors of Intimate Partner Violence}

\begin{abstract}
The aim of this study was to know how the experiences in the family of origin of men involved in intimate partner violence was constituted. Nine male perpetrators of domestic violence were interviewed, responding to lawsuits based on the Brazilian Federal Act 11,340 of 2006 (as known as the Maria da Penha Law). Results were examined using thematic analysis. In this paper, three themes will be presented: affective neglect, exposure to physical violence in childhood and male reference figure. The results were analyzed from the perspective of the Bioecological Theory of Human Development. It was concluded that the construction of the masculinities of these men was influenced by their previous experiences, ruled by severe, abusive and negligent parental models. The male reference figure is also seen as absent and rigid, exercising control over the family microsystem. These experiences may reveal the construction of a model in which men believe that their role must also be played through control and domination based on violence. In this way, this can be considered a risk factor for involvement in intimate partner violence since it reveals the fragility in the construction of the trust bond and reverberation in the relationships lived during the adult life. It is important that these men have spaces for reflection on their actions in the marital intimate context, in order to resignify the experiences of the abuse suffered during childhood.
\end{abstract}

Keywords: Child Abuse, Domestic Violence, Parenting, Masculinity. 


\title{
Violencias Intrafamiliares Vividas en la Infancia por Hombres Autores de Violencia en Pareja
}

\begin{abstract}
Resumen: El objetivo del presente estudio fue conocer cómo se constituyeron las vivencias en la familia de origen de hombres involucrados en relaciones conyugales violentas. Se trata de una investigación cualitativa exploratoria. Se entrevistó a nueve hombres autores de violencia doméstica, que respondían a procesos judiciales con base en la Ley Brasileña 11.340 de 2006 (conocida como Ley Maria da Penha). Se utilizó el análisis temático como método de análisis de datos, y se abordó tres temas en este trabajo: negligencia afectiva, exposición a la violencia física en la infancia y figura masculina de referencia. Los resultados fueron analizados bajola perspectiva dela teoría bioecológica del desarrollo humano. Se concluye que la construcción de las masculinidades de estos hombres sufrió influencia de sus vivencias anteriores, pautadas por modelos parentales severos, abusivos y negligentes. La figura de referencia masculina también es vista como ausente y rígida, ejerciendo el control sobre el microsistema familiar. Estas experiencias pueden revelar la construcción de un modelo en el que el hombre cree que su papel también debe desempeñarse por medio del control y el dominio basados en la violencia. De esta forma, esto puede ser considerado un factor de riesgo para la participación en relaciones conyugales violentas, ya que revela la fragilidad en la construcción del vínculo de confianza y reverbera en las relaciones vividas durante la vida adulta. Es importante que estos hombres tengan espacios de reflexión sobre sus acciones en el ámbito conyugal, a fin de resignificar las experiencias de abuso sufridas en la infancia.
\end{abstract}

Palabras clave: Maltrato a los Niños, Violencia Doméstica, Responsabilidad Parental, Masculinidad.

\section{Introdução}

Durante o processo de desenvolvimento de um indivíduo, a construção do "ser homem" na sociedade brasileira significa ser forte e agressivo, sendo este estimulado a não expressar suas emoções e a usar em diversas situações a violência para resolver conflitos (Coelho \& Carloto, 2007; Medrado, Lyra, Azevedo, \& Brasilino, 2010; Oliveira \& Gomes, 2011). Observam-se, com certa frequência, homens como perpetradores de violência - contra outros homens, contra eles próprios e contra mulheres -, contudo ainda se faz necessário compreender como a socialização dos homens encoraja essa violência. A legitimidade social do comportamento violento, ainda hoje, é vista pelas pessoas como sinônimo de iniciativa, sendo elemento de constituição associado a características de força física (Nolasco, 1993). Durante os processos de masculinização disseminados ao longo da história da humanidade, na maioria das vezes os homens desenvolvem-se orientados a se preocupar principalmente com questões relacionadas a coragem, liberdade e, sobretudo, o exercício da autoridade ao longo de sua construção enquanto o que é ser homem (Beiras \& Cantera, 2012).
Em 2002, a Organização Mundial da Saúde divulgou o Relatório Mundial sobre Violência e Saúde, no qual define violência como "uso intencional da força física ou do poder real ou em ameaça, contra si próprio, contra outra pessoa, ou contra um grupo ou uma comunidade, que resulte ou tenha qualquer possibilidade de resultar em lesão, morte, dano psicológico, deficiência de desenvolvimento ou privação" (OMS, 2002, p. 5). Desta forma, violência compreende ações ou omissões que impossibilitem, impeçam ou mesmo retardem o pleno desenvolvimento humano, além de constituir grave problema e grande desafio para o setor da saúde, por suas repercussões e impactos em todos os âmbitos da vida dos indivíduos, grupos e nações (Souza, Melo, Silva, Franco, Alazraqui, \& González-Pérez, 2012). Minayo (2013) refere que a violência é uma questão sociopolítica que afeta materialmente a saúde dos cidadãos, trazendo elevados custos para as famílias, a sociedade, o sistema judiciário e penitenciário, além de impregnar a cultura, criando várias formas de discriminação e preconceito.

Mais especificamente, o uso de violência contra a mulher tem sido considerado uma prática recorrente 
de alguns homens em suas relações afetivo-sexuais, quando percebem seu poder e controle sendo ameaçados. Nesses momentos, a própria identidade masculina é vivenciada como vulnerável, por estar associada a sentimentos de medo, confusão, vergonha, frustração, impotência, insatisfação e ciúme (Oliveira \& Gomes, 2011). Segundo estes mesmos autores, a "negação" desses sentimentos, que demonstram a fragilidade masculina, favorece a acumulação de estados afetivos que, por não serem expressos, podem culminar em explosões de violência, caracterizando-se, desta forma, como um dos fatores associados à violência contra mulheres.

Desta forma, o presente estudo visou conhecer como se constituíram as vivências na família de origem de homens envolvidos em relações conjugais violentas. Foram utilizados os pressupostos da Teoria Bioecológica do Desenvolvimento Humano (TBDH), de Urie Bronfenbrenner (1996; 2011; Bronfenbrenner \& Morris, 2006), como base para melhor compreender os processos de desenvolvimento dos participantes.

Tal abordagem parte de um modelo que envolve quatro dimensões de análise, o qual é denominado "Modelo PPCT" - Processo, Pessoa, Contexto e Tempo. Desta forma, um dos conceitos mais importantes da teoria de Bronfenbrenner é o que envolve processo, chamado processos proximais (Bronfenbrenner, 2011). Processo proximal é definido como a interação entre o indivíduo e as atividades que acontecem regularmente em seu ambiente imediato, como a pessoa experiencia essas atividades e eventos. Portanto, torna-se importante na análise do fenômeno como esse homem compreende a violência conjugal, sua justificativa para tal ato e sua visão sobre a mulher que sofre a violência. Já no que diz respeito à pessoa, Bronfenbrenner reconheceu a relevância dos fatores biológicos e genéticos no desenvolvimento, além das características psicológicas e a influência social. Portanto, a dimensão "pessoa" é analisada pelas suas características biopsicossociais, tais como idade, escolaridade, ocupação, entre outras informações que vão constituir esse homem. Contexto envolve quatro sistemas inter-relacionados, os quais são definidos como microssistema (nível de relação mais direta do indivíduo - no caso deste estudo, a família de origem), mesossistema (conjunto de microssistemas dos quais a pessoa participa, isto é, a rede de apoio, vizinhos, escola), exossistema (relações entre dois ou mais contextos, em que haja pelo menos um em que a pessoa não tenha contato direto, mas que influencie seus processos em seu contexto mais imediato) e macrossistema (formado por cultura, subcultura, valores, ideologias, entre outros aspectos que podem possibilitar a banalização da violência e a ideia machista de dominação do homem sobre a mulher) (Bronfenbrenner \& Morris, 2006). Com relação ao tempo, Bronfenbrenner (1996) revela a importância de eventos cotidianos e históricos que influenciam a vida da pessoa.

Assim, a família é considerada um microssistema fundamental. Ela permite o desempenho de papéis, atividades e relacionamentos interpessoais associados a determinados comportamentos e expectativas de acordo com a sociedade em que está inserida. Desta forma, a TBDH possibilita uma leitura contextualizada das histórias de vida desses homens, principalmente durante os períodos da infância e adolescência, e da dinâmica familiar experenciada por eles, bem como essa vivência pode influenciar suas relações atuais.

\section{Método}

\section{Delineamento}

Trata-se de estudo de cunho qualitativo, exploratório e transversal. Engloba de forma ampla o fenômeno estudado, familiarizando-se com um assunto ainda pouco explorado: as vivências de violência na infância de homens autores de violência conjugal.

\section{Amostra}

A amostra foi composta por nove homens, que respondem a processos judiciais com base na Lei 11.340/2006 (Lei Maria da Penha), com processo judicial tramitando em Juizados da Vara de Violência Doméstica e Familiar de um foro em uma cidade metropolitana da região Sul do Brasil. Critérios de exclusão foram homens que já tivessem participado de alguma intervenção reflexiva (grupo) sobre gênero, por já terem participado de um espaço de conversa com profissionais que poderia alterar sua percepção sobre a violência cometida e os motivos pelos quais ela ocorreu. Outro critério de exclusão foi terem cometido violência contra outra pessoa que não fosse a cônjuge. A caracterização da amostra está apresentada na Tabela 1. 
Tabela 1.

Dados sociodemográficos dos participantes.

\begin{tabular}{lclll}
\hline \multicolumn{1}{c}{ Nome* } & Idade & \multicolumn{1}{c}{ Escolaridade } & \multicolumn{1}{c}{ Situação conjugal } & Situação ocupacional \\
\hline Cléber & 44 & Ensino fundamental incompleto & Solteiro & Assalariado \\
Mariano & 43 & Ensino fundamental incompleto & Solteiro & Assalariado \\
Henrique & 58 & Ensino médio completo & Solteiro & Assalariado \\
Cláudio & 46 & Ensino médio incompleto & União estável & Aposentado \\
Daniel & 31 & Ensino médio completo & Solteiro & Autônomo \\
Igor & 37 & Ensino fundamental incompleto & Solteiro & Desempregado \\
Elder & 34 & Ensino médio completo & União estável & Assalariado \\
Paolo & 43 & Superior incompleto & Separado & Assalariado \\
Juliano & 57 & Ensino médio completo & Viúvo & Assalariado \\
\hline
\end{tabular}

Nota: A fim de preservar a identidade dos participantes, foram criados nomes fictícios.

\section{Instrumentos}

Questionário de dados sociodemográficos: composto por 15 questões para investigar dados como idade, nível de escolaridade, ocupação, renda, entre outros.

Entrevista semiestruturada: roteiro elaborado pelas pesquisadoras com base nos objetivos da pesquisa. A primeira parte da entrevista abordava as experiências vividas pelos participantes durante sua infância e adolescência, como, por exemplo: "Quando você tinha algum problema ou ficava triste, para quem você pedia ajuda?"; "Conte sobre a sua adolescência: primeiras namoradas, como era o grupo de amigos, o que faziam para se divertir?"; "Descreva a relação dos seus cuidadores com você". Já na segunda parte, as perguntas focavam o momento atual do participante, contemplando questões sobre masculinidade, relação conjugal e violência, como, por exemplo: "Quais são as características que um homem deve ter? E uma mulher?"; "Em um relacionamento, quem você acha que deve ter maior poder de decisão? Por quê?"; "O que você considera ser atitude de violência entre um casal?". A partir das respostas fornecidas, foram investigadas mais profundamente as histórias de vida dos participantes, as percepções e os sentimentos sobre essas vivências, com foco principalmente na forma como esses homens experienciaram cada situação relatada.

\section{Procedimentos de coleta de dados}

Os homens foram selecionados por conveniência. Eram abordados pela pesquisadora e por um aluno de iniciação científica e convidados a participar do estudo, enquanto aguardavam para audiência na sala de espera do foro. As entrevistas foram feitas em apenas um encontro e realizadas em sala reservada na própria Vara de Violência Doméstica e Familiar, com duração, em média, de 30 minutos.

\section{Considerações éticas}

Esta pesquisa faz parte de um estudo maior intitulado "Masculinidades e violência conjugal", que foi aprovado pelo Comitê de Ética em Pesquisa da Universidade Federal de Ciências da Saúde de Porto Alegre (UFCSPA), sob o parecer no 2.076.088. Nesse sentido, seguiu as recomendações éticas da Resolução CNS $n^{\circ} 466 / 2012$. As entrevistas foram realizadas depois da concordância e assinatura do termo de consentimento livre e esclarecido pelos participantes.

\section{Procedimentos de análise de dados}

Utilizou-se análise temática (Braun \&Clarke, 2006). As entrevistas foram gravadas em áudio e, posteriormente, transcritas. Os áudios e transcrições foram revisados em conjunto como forma de promover maior familiarização com os dados coletados. Isso possibilita maior entendimento do significado das falas, tendo em vista ser possível integrá-las com a entonação dada nos relatos. Para análise das transcrições, inicialmente foi necessário dividir as falas em dois temas específicos: masculinidade/questões de gênero e situações de violência. A partir daí, foi possível codificar as falas dos participantes, chegando assim em seis temas de análise: culpabilização das mulheres, a visão de como é 
ser homem ou ser mulher, exploração do trabalho infantil, negligência afetiva, exposição a violência física na infância e figura masculina de referência. Para este artigo, serão desenvolvidos os três últimos temas, ficando os demais reservados para publicações futuras.

\section{Resultados}

Os resultados dos dados demográficos revelam o perfil biopsicossocial dos participantes. $\mathrm{O}$ intervalo de idade variou de 31 a 58 anos. A escolaridade apareceu de forma diversificada, compreendendo homens que relataram ter desde ensino fundamental incompleto até ensino superior incompleto. Apenas um dos participantes declarou não possuir nenhum tipo de renda; os demais informaram receber de 1 a 5 salários-mínimos.

A maioria dos homens entrevistados está na fase de meia-idade, em termos de ciclo vital, e possui ensino médio completo. O perfil difere daquele encontrado na literatura, que aponta que a maioria dos agressores eram homens, entre 16 e 57 anos, com ensino fundamental incompleto (Madureira, Raimondo, Ferraz, Marcovicz, Labronici, \& Mantovani, 2014; Silva, Coelho, \& Moretti-Pires, 2014; Silva, Gomes, Mota, Gomes, \& Amarijo, 2015). Já a respeito da situação ocupacional, corrobora estes e outros estudos, traçando um perfil de homens formalmente inseridos no mercado de trabalho.

A partir das análises das entrevistas, foi possível perceber diversas vivências consideradas como fatores de risco (Maia \& Williams, 2005; Pacheco, Irigaray, Werlang, Nunes, \& Argimon, 2014; Pasian, Bazon, Pasian, \& Lacharité, 2015) para o envolvimento em situações de violência conjugal na vida adulta. Entre elas, destacam-se: experiências baseadas em negligência afetiva, exposição a violência física, além de uma figura masculina de referência voltada para o modelo tradicional de paternidade. Desta forma, percebeu-se a dificuldade em encontrar modelos de apoio, que pudessem auxiliar na construção de uma masculinidade diferenciada dos padrões hegemônicos. A seguir serão apresentadas e discutidas essas categorias.

\section{Discussão}

\section{Negligência afetiva das figuras de apoio}

Essa categoria temática foi identificada nas falas dos participantes e refere-se ao fato de que, ao serem questionados sobre a quem pediam ajuda quando se sentiam tristes na infância, a maioria deles relatou que "preferia ficar sozinho" ou não percebia a existência de figuras de apoio nesses momentos. Portanto, pode-se compreender que eles talvez não se sentissem acolhidos, pois não havia alguém para conversar e expressar seus sentimentos, como angústia, tristeza, medo, entre outros. Este fato pode revelar que não percebiam a existência de pessoas em sua rede que exercessem a função de apoio emocional, ou elas realmente não existiam.

Apoio emocional refere-se a intercâmbios que conotam uma atitude emocional positiva, clima de compreensão, estímulo e suporte, e são relações sociais próximas e com baixo nível de ambivalência (Sluzki, 2010). Essa concepção de inexistência de apoio pode indicar a presença de negligência afetiva por parte das pessoas que deveriam exercer o papel de cuidadores. Tal situação pode ser observada quando os pais ou cuidadores, geralmente de modo crônico, não demonstram ter disposição ou capacidades psicológicas necessárias ao cuidado. Deste modo, acabam respondendo inadequadamente às necessidades das crianças e não solicitam ajuda de outras pessoas que poderiam/deveriam ajudar no cuidado.

Sendo assim, a negligência infantil se faz presente em contextos nos quais pais e/ou outros membros da família deixam de prover o bem-estar da criança/adolescente, em uma ou mais das seguintes áreas: saúde, educação, desenvolvimento emocional, nutrição, abrigo e condições seguras (Pasian et al., 2015). Já o termo "figura de apoio" refere-se àquela pessoa de referência para quem a criança pede auxílio ou aconchego em situações de estresse decorrentes de suas relações cotidianas (Custódio, Crepaldi, \& Linhares, 2014). Como rede de apoio social e afetiva, entendem-se as relações que compreendem não apenas a família nuclear ou extensa, mas os vínculos interpessoais ampliados, como amigos e colegas de escola, e as relações estabelecidas na comunidade onde o indivíduo vive (Sluzki, 2010).

Dentre os vários ambientes que sustentam e fazem parte do universo de relações do indivíduo, existem no nível de seu microssistema pessoas significativas que formam sua primeira rede social pessoal. Esta é composta por aquelas pessoas que se distinguem das demais na rede extensa, em termos de intensidade e proximidade da relação afetiva experienciada nesse contexto. Tal rede funciona como ponto de apoio e contribui para a experiência individual de identidade 
e competência, na qual se incluem os hábitos de cuidado com a saúde e a adaptação em momentos de crise (Custódio et al., 2014).

Desta forma, não ter com quem contar na ocorrência de episódios estressantes nesta fase torna-se fator de risco, sendo a ausência de rede de apoio social e afetiva apontada como condição negativa no desenvolvimento de crianças e jovens, embora não determinante a priori (Poletto, Koller \& Dell'Aglio, 2009). Igor trouxe em seu relato a vivência de uma infância permeada por diversas mudanças do ponto de vista da rede de apoio. Seu pai matou sua mãe quando ele tinha 5 anos de idade, situação que o levou a ficar aos cuidados da avó. Pouco tempo depois, aos 9 anos, ela veio a falecer devido a problemas de saúde, sendo necessária nova mudança para a casa das tias, as quais, segundo seu relato, não demonstravam interesse em cuidá-lo com apoio e afeto e o exploravam em relação ao trabalho. A "saída precoce de casa" (condição negativa para o desenvolvimento) é um dos fatores de risco associados a essa falta. É possível perceber em seu relato o sofrimento da "falta de figura de apoio" (do pai, da mãe, da avó e das tias).

Eu perdi a minha mãe cedo, com 5 anos, então daí pra frente minha vó me criou, até os 9 anos; eu morei ... um mês em cada tia né, como a minha avó tava no hospital, cada um foi me levando pra ver onde é que eu me adaptava melhor, daí com 13 anos eu saí de casa. Daí comecei a viver a minha vida sozinho. Aprender tudo sozinho, trabalhar sozinho... tinha a minha tia, mas eu sempre me fechei... então foi uma vida muito sofrida. (Igor)

Segundo Poletto et al. (2009), fatores de risco são processos ativos, expressos com dinamicidade nos contextos, cultura, história e características pessoais, que juntos ou isolados provocam resultados disfuncionais, como envolvimento em situações de violência na adultez, por exemplo. De modo inverso, dispor de alguém que ofereça ajuda ou apoio em situações de necessidade pode facilitar o enfrentamento de problemas e diminuir os efeitos negativos de situações estressantes, favorecendo a saúde e o bem-estar emocional (Bazon, Mello, Bérgamo, \& Faleiros, 2010).

Como citado anteriormente, na pesquisa havia uma questão em que os participantes deveriam contar uma situação na qual se sentiram tristes e para quem pediram apoio. Sendo assim, ao ser questionado sobre isso, o participante Cléber relatou a prisão de seu avô, uma situação considerada por ele como muito marcante e cheia de lembranças negativas. No caso, seu avô foi levado pela polícia quando estava em casa, na frente da família, o que gerou no participante sentimento de perda, visto ser o avô uma pessoa de quem ele gostava muito. Após o fato, disse que não foi amparado/consolado por ninguém, como relatado na fala a seguir: “. . pedia pra Deus só [ajuda quando estava triste ou com medo], só pra Deus. Eu tinha uma imagem de uma santinha, entendeu, que eu pedia pra ela as coisas; nessas partes de tristeza eu sempre gostava de ficar sozinho...".

De acordo com a TBDH (Bronfenbrenner, 1996), família é caracterizada como o primeiro ambiente do qual a criança participa ativamente, interagindo por meio de relações diretas ao participar da rotina estabelecida pela dinâmica familiar. A princípio, o microssistema familiar deve apresentar-se como a maior fonte de segurança, proteção, afeto, bem-estar e apoio para a criança. Dentro dele, ela desenvolve o senso de permanência e o de estabilidade, fornecidos pelo sentimento de segurança dos pais aos filhos, de que não haverá rupturas ou rompimentos, mesmo em situações de estresse (Cecconello, De Antoni, \& Koller, 2003). A garantia de permanência e estabilidade faz a família funcionar como um sistema integrado, cujo objetivo principal é promover o bem-estar de seus membros. No caso dos homens participantes da pesquisa, foi possível perceber que esse senso de permanência e estabilidade é abalado pela percepção que têm da falta de uma figura de apoio, principalmente em situações de estresse. A fala de Cláudio ilustra a questão: "Na verdade, eu fui sempre meio individualista, sempre fui de tentar resolver meus problemas mesmo né, então eu não tinha ninguém, assim, para confessar ou para me abrir".

A TBDH considera que o desenvolvimento humano é um processo de continuidades e mudanças das características das pessoas e dos grupos, que ocorre ao longo do ciclo de vida e das gerações (Bronfenbrenner, 2011). Durante a infância, a interação com cuidadores primários e outros agentes de socialização (escola, vizinhança, educadores de práticas esportivas, por exemplo) é uma referência básica para a criança em relação aos modos de se aproximar do mundo e ser um agente ativo dele (Riquelme \& Munita, 2017) e, assim, desenvolver os processos proximais. Desta forma, entende-se que 
não identificar esta figura em seu ambiente mais imediato (no caso, a família) faz que o indivíduo precise lidar sozinho com suas frustrações, sendo que muitas vezes não tem capacidade emocional/cognitiva para isso. Assim, devido à fase de desenvolvimento na qual se encontra, essa situação gera sentimentos de solidão e desamparo.

Embora a perspectiva sistêmica não seja determinista em relação a causalidade e efeito, a circularidade dessas vivências pode promover ações pautadas no sentimento de desamparo, ou de não acolhimento de suas demandas emocionais. O estudo feito por Madalena, Carvalho e Falcke (2018) demonstrou que homens sofrem influência das experiências abusivas na família de origem de forma mais significativa do que mulheres. Este dado corrobora os de outros estudos que avaliaram o impacto das experiências de abuso na infância considerando-as como fatores de risco para perpetração da violência conjugal (Fang \& Corso, 2008; Fergusson, Boden, \& Horwood, 2008).

Neste sentido, a negligência afetiva é considerada uma forma de violência silenciosa, não deixando marcas físicas visíveis, porém prejuízos psicológicos e sociais em longo prazo. Nos discursos dos homens entrevistados, foi possível identificar que, além desse tipo de violência, também houve diversas situações em que estiveram expostos a episódios de abuso físico, seja parental ou entre pares. Sendo assim, torna-se relevante perceber os atravessamentos que perpassam as relações primárias da família de origem, visto que a TDBH propõe que se considerem os outros sistemas presentes na vida das pessoas para melhor compreensão dos fenômenos.

\section{Abuso físico parental, entre os pais e entre os pares}

Durante as entrevistas, oito dos nove participantes relataram situações de abuso físico parental e/ou entre pares. Afirmaram ter sofrido esse tipo de violência, porém em suas falas fica perceptível a banalização de tal ato, já que era a forma de punição recorrente na época em que eram crianças. A fala de Mariano exemplifica bem isso:

É que a mãe batia. Claro, era moleque né, a mãe batia e não perdoava, dependendo da arte, era o lado da fivela da cinta; muito apanhei, mas não me arrependo; hoje eu sou gente graças às surras que levava dela; não que fosse agressiva porque ela queria ser, é que naquele tempo se dava corretivo nos filhos, podia dar corretivo nos filhos. (Mariano)

O conceito de abuso físico envolve um padrão hierárquico de relacionamento no qual o agressor (a pessoa que deveria ter o papel de cuidador) estaria em uma posição de superioridade em relação à vítima (criança), que, por estar em condição especial de desenvolvimento, seria mais vulnerável a qualquer tipo de agressão a seus direitos (Patrian, Rios, \& Williams, 2013). Segundo o guia de prevenção a maus-tratos infantis (World Health Organization \& International Society for Prevention of Child Abuse and Neglect, 2009), abuso físico pode ser caracterizado pelo uso intencional da força física contra uma criança que resulte ou tenha possibilidade de resultar em prejuízos a sua saúde, sobrevivência, desenvolvimento ou dignidade. Nesta definição estão incluídos: bater, espancar, chutar, chacoalhar, morder, estrangular, escaldar, queimar, intoxicar e sufocar. Observa-se que violência física (ou abuso físico) é geralmente utilizada no contexto doméstico com o objetivo de punir ou disciplinar a criança por algum erro cometido, sendo método utilizado entre cuidadores com o objetivo de modificar o comportamento da criança (Cecconello et al., 2003).

Porém, tais atos de violência muitas vezes refletem raiva ou falta de habilidade do cuidador, e não uma estratégia para fazer a criança entender o que se espera dela. Tais punições envolvem controle externo e relação de poder e dominação. Contudo, há inúmeros estudos demonstrando que a perpetuação de tais atos durante a infância reflete, em longo prazo, em consequências negativas para o desenvolvimento (Bartlett \& Easterbrooks, 2012; Bérgamo \& Bazon, 2011; Keene \& Epps, 2016; Wang, Wang \& Liu, 2016). Sendo assim, ao contrário de disciplinar, o abuso físico aparece como um fator de risco para diversos problemas em nível de saúde física e mental.

É possível verificar claramente a conduta abusiva dos cuidadores como justificativa de disciplina em muitos dos relatos feitos pelos homens que participaram da pesquisa. Henrique conta que, aos 10 anos de idade, trabalhava vendendo frutas e verduras de porta em porta, na cidade em que residia, no interior do estado. No final de cada dia trabalhado, deveria levar o dinheiro arrecadado para o pai. Em determinada situação, uma das clientes, compradora assídua 
de sua mercadoria, combinou com ele que lhe faria o pagamento no outro dia, já que estava sem troco. Ao chegar em casa, foi espancado por seu pai, o qual não lhe deu a chance de justificar a falta do dinheiro, considerando que o menino havia ficado com o dinheiro da venda: "Eu tomei uma tunda muito grande, eu me lembro, eu procuro não me lembrar disso aí. Mas eu tomei uma tunda muito grande, sabe, muito grande assim, muito grande, uma tunda assim ó, e ele me segurou pelo pescoço e disse pra mim 'ó isso é pra tu aprender a não pegar o que não é teu’”.

Outro participante, Cléber, demonstra em seu relato que as práticas punitivas eram recorrentes e sempre com o argumento de que eram necessárias para obtenção de disciplina: "Eu aprendi a amarrar um tênis apanhando”. A partir das falas de Henrique e de Cléber, é possível perceber quanto o abuso físico era usado como "prática educativa" com o objetivo de corrigir comportamentos considerados como "desobediência".

Após a aprovação do Estatuto da Criança e do Adolescente - ECA (Lei no 8.069, 1990), tem ocorrido um movimento de busca de mudança social acerca das punições contra crianças e adolescentes. Também é possível citar a Lei no 13.010/2014 (conhecida como Lei Menino Bernardo), que alterou o ECA em seu artigo 13, bem como inseriu os artigos 18-A, 18-B e 70-A, estabelecendo que crianças e adolescentes têm direito de ser educados e cuidados sem o uso de castigos físicos ou de tratamento cruel ou degradante. Entretanto, ainda há concepções e práticas que apontam para uma dificuldade em considerá-las como sujeitos de direitos, já que ainda são vistas como objeto de dominação dos adultos (Souza, Lauda, \& Koller, 2014).

Alguns estudos têm demonstrado quanto ser exposto a situações de abuso físico durante a infância é fator de risco para o envolvimento do indivíduo em casos de violência/agressão física na idade adulta (Metz \& Razon, 2015; Neigh, Ritschel, \& Nemeroff, 2010; Razera, Cenci, \& Falcke, 2014; Scarborough, Lloyd, \& Barth, 2009). Como já mencionado, de nove participantes entrevistados, oito relataram pelo menos uma lembrança vinculada a esse tipo de violência. Tal fato corrobora os achados dos estudos citados, os quais abordam a influência transgeracional em relação à incidência de comportamento violento na idade adulta. A reprodução de atos de violência pode ser notada principalmente em crianças que experenciaram esses episódios e é utilizada por elas na adultez como forma de resolução de conflitos (Madalena et al., 2018).

Segundo a TBDH, a família é o principal contexto de desenvolvimento humano, onde ocorrem as primeiras interações sociais da criança. Nela se inicia a aprendizagem de conceitos e regras que fundamentam os processos de socialização dos indivíduos. O relacionamento entre pais e filhos é um processo proximal, resultando em diferentes desfechos de desenvolvimento. Nos casos em que o ambiente é desfavorável, como, por exemplo, permeado de atitudes que envolvem atos de violência, as manifestações de disfunção tendem a ser mais frequentes e severas (Bronfenbrenner, 2011). Estas podem aparecer por meio do descontrole de impulsos, os quais aumentam a possibilidade de resolver os conflitos com comportamentos agressivos, como aqueles percebidos nos casos discutidos no presente estudo.

Diversas manifestações de violência podem existir em famílias promotoras de um ambiente desfavorável para o desenvolvimento. Entretanto, ser testemunha de episódios de violência entre os cuidadores durante a infância é um exemplo de situação que pode ser geradora de muita angústia para a criança. Como observado no estudo de Metz et al. (2015), nestes casos há uma inversão de papéis, já que a criança se sente responsável e culpada por ver a mãe agredida por outra pessoa por quem ela também nutre sentimentos positivos. Desta forma, a sensação de ambivalência e impotência aparece porque a criança quer proteger quem é agredido, mas ao mesmo tempo não quer denunciar aquele que agride.

Poletto et al. (2009) avaliaram a ocorrência de eventos estressores e seu impacto na vida de crianças e adolescentes em situação de vulnerabilidade social. O estudo demonstrou que a morte de familiares, principalmente por episódios de violência, como assassinatos e brigas, apareceu como evento estressor de alto impacto, segundo a avaliação dos próprios participantes da pesquisa. Tais dados vão ao encontro do relato de Igor, que diz que perdeu a mãe muito cedo, assassinada pelo próprio marido: "Meu pai é... matou minha mãe quando eu era pequeno”. Outro estudo que avaliou o impacto de eventos de vida estressores em adolescentes corrobora os resultados da pesquisa anterior, concluindo que situações de privação e violência, mesmo que de forma ocasional, são considerados de forte impacto pelos adolescentes (Busnello, Schaefer, \& Kristensen, 2009). 
Outra situação bastante recorrente durante a infância e adolescência são brigas entre pares. Todavia, elas podem ser entendidas como acontecimentos comuns nessas fases, uma vez que funcionam como laboratório de experiências relacionais (Poletto et al., 2009). É preciso verificar cada caso, pois o relacionamento entre pares e irmãos também é apontado como fator de proteção. Com irmãos e pares, as crianças trocam, dividem, empurram e mantêm contatos físicos como expressões de afeto (carícias, beijos e abraços). Tais comportamentos e trocas revelam aspectos importantes na socialização e no desenvolvimento humano (Poletto \& Koller, 2008).

A escola é um dos microssistemas que mais oportunizam para a criança/adolescente o convívio com pares. São estabelecidos os mais variados tipos de processos proximais, considerados fatores tanto de proteção quanto de risco (Petrucci, Borsa, \& Koller, 2016). Dentro dos fatores de risco presentes no ambiente escolar encontram-se os comportamentos agressivos entre pares, os quais se constituem como um problema de prevalência elevada, ocasionando em dificuldades de aprendizagem, abandono escolar precoce, prejuízo nas relações interpessoais e no desenvolvimento socioemocional de crianças e jovens (Silva, Oliveira, Bandeira, \& Souza, 2012). O bullying é considerado um subtipo de comportamento agressivo, e pode ser definido como o abuso sistemático de poder entre pares, provocado por um indivíduo ou mais, contra uma pessoa ou grupo de pessoas, em um processo de agressão intencional e continuado (Olweus, 1993; Smith, Depra, \& Rigby, 2004). É caracterizado pelo desequilíbrio de força ou de poder entre o agressor e a vítima (Olweus, 1993), a qual pode ser física ou emocionalmente mais fraca do que aquele que agride. A prática desse tipo de comportamento pode acarretar prejuízos tanto para as vítimas quanto para os agressores, tais como dificuldades nos relacionamentos sociais, transtornos de conduta, problemas escolares, queixas psicossomáticas, baixa autoestima e maior vulnerabilidade emocional (Lisboa, 2005; Protegerou \& Flisher, 2012). Mariano revela, em sua fala, quanto foi marcante para ele ter sido vítima de bullying na época da escola. Destaca-se que, na época (cerca de trinta anos atrás), tal conceito ainda era muito incipiente, o que não favorecia a avaliação de gravidade da queixa dos alunos, por parte dos cuidadores e da comunidade escolar:
Eu apanhava muito no Colégio... eu não me concentrava. Eu chorava, eu era agredido... eu era muito perseguido, todo dia eu apanhava porque eu era muito quieto, eu era muito quieto. Ficava deslocado, né . . . não que eu viesse provocar... é que também os colegas eram agressivos ... eu acabava apanhando, o colega tava na fila, aí daqui a pouco ele se virava e me cuspia. Limpava... eu ficava quieto, sempre baixando a cabeça, sempre baixando a cabeça. Daí de tanto apanhar eu comecei a revidar, mas daí era pior porque eu revidava, chamavam a mãe e o que acontecia? Eu apanhava de novo. (Mariano)

O estudo de Godoy e Alencastro (2016) descreveu as características da violência exercida por adolescentes escolares da capital de Mato Grosso, Brasil, e verificou que os adolescentes agressores eram, em sua maioria, do sexo masculino, na faixa etária dos 16 aos 17 anos. Outros estudos também identificaram que o sexo masculino exerce mais violência que o feminino (Bandeira \& Hutz, 2012; Prodócimo, Farenzena, Costa, Silva, \& Mattosinho, 2013; Teixeira-Filho, Rondini, Silva, \& Araújo, 2013). Isso pode ser reflexo das questões de gênero, que influenciam, inclusive, na forma como pais e/ou responsáveis educam seus filhos homens, com uma criação voltada para a masculinidade e a virilidade. Nota-se que meninos utilizam mais a violência para a resolução de conflitos com pessoas que não fazem parte de seu convívio. Em contrapartida, o estudo de Costa, Farenzena, Simões e Pereira (2013) mostrou que a participação do gênero feminino nas práticas de bullyingse revela numa escala semelhante à do gênero masculino. Tal fato pode ser justificado pelo movimento crescente de luta e desmistificação que há em relação a mulheres serem consideradas o "sexo frágil”. Nesse sentido, faz-se necessário promover ações de prevenção da violência entre adolescentes, com sua sensibilização para resolução de conflitos com base na tolerância e no diálogo em detrimento da utilização de atos violentos (Godoy et al., 2016).

\section{Figura masculina de referência}

Esta categoria temática foi identificada na fala dos homens e está diretamente relacionada à forma como eles percebem o convívio com aqueles que representavam sua principal figura masculina. Os nove participantes revelaram que o pai era a referência de homem mais próxima com quem 
conviveram. Com as atuais transformações que vêm ocorrendo em relação aos papéis sociais atribuídos a homens e mulheres e às questões de gênero como um todo, a paternidade tem sido tema de diversos estudos tanto em âmbito nacional quanto internacional (Cater \& Forssell, 2014; Kranz, Busch, \& Niepel, 2018; Prado \& Abrão, 2014; Silva, Silva \& Bueno, 2014).

Como os cuidados com os filhos podem variar muito de homem para homem, conforme o grau de disponibilidade pessoal e de tempo, alguns autores utilizam-se do termo paternidade participativa para nomear o cuidado e o envolvimento constante no cotidiano dos filhos - nos domínios de alimentação, higiene, lazer e educação (Sutter \& Bucher-Maluschke, 2008). Porém, no presente estudo, percebeu-se que o perfil dos pais descritos pelos participantes é aquele do pai tradicional, definido como alguém que assume a responsabilidade de dar permissões, controlar a família por meio de críticas e recomendações à mãe, prover alimentos, impor castigos, disciplinar e, ocasionalmente, brincar e compartilhar de passeios familiares (Muzio, 1997). Cléber diz que "o pai trabalhava muito né, o pai só ficava mais no final de semana”; da mesma forma acontecia nas casas de Paulo, "Meu pai tava sempre trabalhando, viajava muito, para o nosso sustento", e de Cláudio, "Meu pai era naquele tempo antigo né, mas assim ele era meio durão assim né, era meio violento com a minha mãe e tal".

A afetividade vinculada ao papel paterno redimensiona a participação masculina na família, sendo a presença do pai entendida como atitudes de carinho, amor e dedicação, consideradas quesitos essenciais para a construção da personalidade do filho. O contrário também pode ser percebido, já que a falta de afetividade pode construir uma relação não saudável, reprodutora de consequências negativas para o desenvolvimento dos filhos (Gabriel \& Dias 2011; Yoder, Brisson, \& Lopez, 2016). O presente estudo corrobora esta segunda percepção, já que em sua maioria os homens entrevistados tinham como figura masculina de referência o pai, percebendo-o como ausente, já que passava muito tempo fora de casa. Quando estavam presentes, pouco se envolviam em atividades com eles ou eram agressivos, mostrando padrões de comportamento altamente rígidos, além do uso abusivo de bebidas alcoólicas. Assim refere Cláudio:

Mas na verdade nunca tive intimidade muito boa com ele [pai], intimidade que eu digo é... de eu não aceitar né, na verdade é que ele brigava sem motivo, entendeu? Ele bebia e aquela coisa toda, mas assim comigo, claro, ele cobrava, exigia que tu trabalhasse; ele sempre foi meio durão assim e eu me afastava dele, mas eu não gostava muito de achego com ele porque ele bebia muito, né, ele chegava do trabalho embriagado.

É notável que a figura paterna das gerações anteriores tinha a missão de educar e disciplinar os filhos, tarefa que não exigia necessariamente presença constante e afeto nas intervenções. Muitos homens tendem a ter o próprio pai como modelo de homem, o que revela a significativa influência que os pais têm na construção da imagem de masculinidade que o filho desenvolverá no futuro (Gabriel \& Dias, 2011). Isso quer dizer que há padrões de valores e características que são passados de geração em geração, com algumas adaptações ao mundo atual, mas ainda mantendo características essenciais do cuidado dos filhos (Yoder et al., 2016).

O estudo realizado por Sutter e Bucher-Maluschke (2008), que procurou entender o sentido dado à paternidade e à masculinidade de homens que vivenciam o cuidado cotidiano dos filhos, observou que prover materialmente e proteger a família ainda são vistos como as principais tarefas de um homem, embora haja também o questionamento desse lugar socialmente atribuído. Ao homem ainda cabe o papel de principal provedor, tanto que a paternidade continua associada à imagem do trabalho, como na perspectiva tradicional. Percebe-se nos discursos de dois participantes quanto a ausência física do pai é compreensível, tendo em vista que se justifica pelo sustento da família. "Meu pai tava sempre trabalhando, viajava muito, para o nosso sustento. Mas ele tava sempre presente, se não vinha uma vez no mês, vinha duas, ele tava sempre junto" (Elder). Já Paolo diz que "O pai saía às seis horas da manhã e voltava tarde; nos damos muito bem, tanto que até hoje ele mora comigo".

Porém a experiência de ser filho em um modelo tradicional, geralmente frio e distante, faz alguns homens desejarem agir de forma diferente. Nota-se, durante os relatos a seguir, que dois participantes condenam a forma como seus pais exerciam os cuidados parentais. Dizem querer ser diferentes, porém no curso de suas vidas acabaram envolvidos em processos que versam sobre o tema da violência, reproduzindo o mesmo padrão de comportamento observado em seu pai: 
Porque eu não tenho ele [o pai] como um exemplo, eu não tenho ele como exemplo, ao contrário, eu tenho meu tio como exemplo de pessoa; meu pai era um homem muito ruim pra nós e pra mãe. Ela teve uma vida bastante difícil com ele. E essa foi uma das coisas que eu sempre pedi a Deus: pra eu não ser que nem meu pai. (Henrique)

Meu pai é... matou minha mãe quando eu era pequeno e eu não quero ser igual ao meu pai. Entendeu? Meu pai foi preso por causa disso. Por ciúmes, matou a minha mãe. E eu não quero ser igual a ele. Eu quero ser melhor que ele. (Igor)

Como já referido anteriormente, sabe-se que é na família de origem que as crianças vivenciam suas primeiras relações com o mundo. Dessa forma, os padrões relacionais que se estabelecem neste microssistema tornam-se precursores dos demais relacionamentos que o indivíduo terá ao longo da vida (Bronfenbrenner, 2011). Embora os modelos parentais específicos da mãe e do pai não sejam os únicos determinantes para um ajustamento emocional positivo ou negativo, o tipo de vínculo formado com um ou ambos os cuidadores de referência pode ter impacto importante na forma como serão desenvolvidas as relações sociais futuras. Por exemplo, interações entre pai e filho baseadas em comportamento agressivo ou violência física tendem a promover sentimentos de raiva e/ou comportamentos externalizantes (Yoder et al., 2016). De fato, as relações pai-filho tendem a ser caracterizadas por atividades que envolvem brincadeiras que sirvam como forma de reprodução do estereótipo de masculinidade, tais como jogos de futebol, carrinhos, armas de guerra etc. (Lamb, 2000; 2010).

Apesar disso, ser pai é um papel que se encontra em ampla transformação. Não é mais aceito que ele apenas pague as despesas do filho; ele deve despender um tempo com a criança, atuar em sua educação e cuidados, além de estar disponível emocionalmente para ela - aspectos essenciais para um adequado desenvolvimento emocional (Freitas, Silva, Coelho, Guedes, \& Costa, 2009; Staudt \& Wagner, 2008). Desta forma, propõe-se o uso de outros termos, como exercício da parentalidade em vez de exercício da paternidade/maternidade, com o objetivo de que haja um deslocamento das desigualdades de gênero nessa prática (Moreira \& Toneli, 2013).
Como já mencionado, desenvolver-se em ambiente exposto a situações de violência é considerado fator de risco para o surgimento de problemas emocionais, como baixa autoestima, insegurança e dificuldades de relacionamento interpessoal. Os exemplos apresentados neste estudo foram direcionados ao relacionamento dos participantes em suas famílias de origem como o principal processo proximal vivenciado por eles durante a infância e a adolescência. Desta forma, observou-se quanto o ambiente familiar pode ser considerado fator de risco, caso seja permeado de situações adversas como violência, uso de drogas ou padrões agressivos de comportamento. Além disso, os modelos parentais podem não servir como exemplos a serem seguidos, despertando a necessidade do indivíduo de fazer diferente, conforme relatado em algumas entrevistas.

Apesar de escassos, estudos discutindo o tema da paternidade e dos modelos de masculinidade na infância e na adolescência oferecem indicativos da significância de um modelo de pai que esteja não só envolvido em prover o sustento da casa, mas também comprometido com a educação e o cuidado dos filhos. Cada contexto familiar costuma ter suas próprias regras de funcionamento, contendo determinações sobre quem fica responsável por cada tarefa, e ainda é muito comum vermos somente mulheres com múltiplas funções. Os atuais modelos familiares encontram-se em constante transformação, revelando novas formas de exercício da paternidade, refletindo também em novas construções de masculinidade. Destaca-se, portanto, a necessidade de maior compreensão acerca da influência única e interativa dessas variáveis como fatores de risco para o envolvimento em situações de violência.

\section{Considerações finais}

A família é uma das instituições sociais responsáveis pela socialização primária das pessoas (Bronfenbrenner\&Morris, 2006; Bronfenbrenner, 2011), destacando-se alguns fatores importantes para a criança. Dentre eles estão a qualidade do relacionamento com os pais, o clima familiar, as características dos indivíduos e do ambiente físico da família e os eventos ocorridos na vida das pessoas ou na sociedade (Petrucci et al., 2016).

Conclui-se que a construção da masculinidade desses homens sofreu influência de suas vivências anteriores, durante a infância e a adolescência, 
pautadas por figuras parentais severas, abusivas e negligentes. Estas são, justamente, pessoas que deveriam exercer o papel de proteção e cuidado. A figura de referência masculina também é vista como ausente e rígida, exercendo controle sobre o microssistema familiar. Essas experiências podem revelar a construção de um modelo no qual o homem acredita que seu papel também deva ser desempenhado por controle e domínio baseados na violência. Isso pode ser considerado um fator de risco para o envolvimento em relações conjugais violentas, já que revela a fragilidade na construção do vínculo de confiança e reverbera nos relacionamentos vividos durante a vida adulta.

Este estudo é um recorte de uma pesquisa maior, composta por uma riqueza de dados que estão sendo analisados para futuras publicações. Dentre as limitações encontradas, destacam-se o contexto e o local de entrevista, que podem ter influenciado as respostas dos participantes, que buscaram responder as questões de acordo com a desejabilidade social, tendo em vista a situação coercitiva do ambiente forense e do processo ao qual estavam respondendo. Além disso, notou-se diferença nas falas e comportamento dos homens em relação ao gênero da pessoa que estava conduzindo a entrevista. Quando o entrevistador era homem, o conteúdo das respostas tornava-se mais de acordo com os padrões de masculinidade já citados. Sugere-se expandir a pesquisa para outros contextos nos quais os homens não estejam passando por situação judicial, bem como um estudo comparativo envolvendo as respostas fornecidas a entrevistadores(as) homens e mulheres.

Por fim, torna-se importante que esses homens tenham espaços de reflexão sobre suas ações em âmbito conjugal, a fim de ressignificar as experiências de abuso sofridas, promovendo, assim, relações mais saudáveis em sua estrutura familiar como um todo.

\section{Referências}

Bandeira, C. M., \& Hutz, C. S. (2012). Bullying: prevalência, implicações e diferenças entre os gêneros. Psicologia Escolar e Educacional, 16(1), 35-44. https://dx.doi.org/10.1590/S1413-85572012000100004

Bartlett, J. D., \& Easterbrooks, M. A. (2012). Links between physical abuse in childhood and child neglect among adolescent mothers. Children and Youth Services Review, 34(11), 2164-2169. https://doi.org/10.1016/ j.childyouth.2012.07.011

Bazon, M. R., Mello, I. L. M. A., Bérgamo, L. P. D., \& Faleiros, J. M. (2010). Negligência infantil: estudo comparativo do nível socioeconômico, estresse parental e apoio social. Temas em Psicologia, 18, 71-84.

Beiras, A., \& Cantera, L. M. (2012). Narrativas personales, construcción de masculinidades - Aportaciones para la atención psicosocial a hombres autores de violencia. PSICO, 43, 251-259.

Bérgamo, L. P.D., \& Bazon, M. R. (2011). Experiências infantis e risco de abuso físico: mecanismos envolvidos na repetição da violência. Psicologia:Reflexãoe Crítica, 24(4), 710-719.https://dx.doi.org/10.1590/S0102-79722011000400011

Braun, V., \& Clarke, V. (2006). Using thematic analysis in psychology. Qualitative Research in Pshychology, 3, 77-101. http://dx.doi.org/10.1191/1478088706qp063oa

Bronfenbrenner, U. (2011). Fortalecendo os sistemas da família. In U. Bronfenbrenner. Bioecologia do desenvolvimento humano: tornando os seres humanos mais humanos (pp. 277-289). Porto Alegre, RS: Artmed.

Bronfenbrenner, U. (1996). A ecologia do desenvolvimento humano: experimentos naturais e planejados. Porto Alegre: Artes Médicas.

Bronfenbrenner, U., \& Morris, P. A. (2006). The bioecological model of human development. In W. Damon (Series Ed.) \& R. M. Lerner (Vol. Ed.). Handbook of child psychology (Vol. 1, pp. 793-828). New York: John Wiley \& Sons.

Busnello, F. B., Schaefer, L. S., \& Kristensen, C. H. (2009). Eventos estressores e estratégias de coping em adolescentes: implicações na aprendizagem. Psicologia Escolar e Educacional, 13(2), 315-323. https://dx.doi.org/10.1590/ S1413-85572009000200014

Cater, A., \& Forssell, A. M. (2014). Descriptions of fathers' care by children exposed to intimate partner violence (IPV) - relative neglect and children's needs. Child and Family Social Work, 19, 185-193. https://dx.doi.org/10.1111/j.1365-2206.2012.00892.x

Cecconello, A. M., De Antoni, C., \& Koller, S. H. (2003). Práticas educativas, estilos parentais e abuso físico no contexto familiar. Psicologia em Estudo, 8(spe), 45-54. https://dx.doi.org/10.1590/S1413-73722003000300007 
Coelho, S. M. P. F., \& Carloto, C.M. (2007). Os sentidos da masculinidade nas relações de gênero e a violência afetivo-conjugal. Emancipação, 7, 115-136.

Costa, P., Farenzena, R., Simões, H., \& Pereira, B. (2013). Adolescentes portugueses e o bullying escolar: estereótipos e diferenças de género. Interaç̧ões, 9(25), 180-201.

Custódio, Z. A. O., Crepaldi, M. A., \& Linhares, M. B. M. (2014). Redes sociais de apoio no contexto da prematuridade: perspectiva do modelo bioecológico do desenvolvimento humano. Estudos de Psicologia, 31(2), 247-255. https://dx.doi.org/10.1590/0103-166X2014000200010

Fang, X., \& Corso, P. S. (2008). Gender differences in the connections between violence experienced as a child and perpetration of intimate partner violence in young adulthood. Journal of Family Violence, 23(5), 303-313. https://doi.org/10.1007/s10896-008-9152-0

Fergusson, C. J., Boden, J. M., \& Horwood, L. J. (2008). Developmental antecedents of inter-partner violence in a New Zealand Birth Cohort. Journal of Family Violence, 23, 737-753. https://doi.org/10.1007/s10896-008-9199-y

Freitas, W. M. F., Silva, A. T. M. C., Coelho, E. A. C., Guedes, R. N., \& Costa, A. M. T. (2009). Paternidade: responsabilidade social do homem no papel de provedor. Revista de Saúde Pública, 43(1), 85-90.

Gabriel, M. R., \& Dias, A. C. G. (2011). Percepções sobre a paternidade: descrevendo a si mesmo e o próprio pai como pai. Estudos de Psicologia, 16(3), 253-261.

Godoy, C. B., \& Alencastro, L. C. S. (2016). Características da violência exercida por adolescentes escolares. Revista de Enfermagem, 24(4), 11050. http:// dx.doi.org/10.12957/ reuerj.2016.11050

Keene, A. C., \& Epps, J. (2016). Childhood physical abuse and aggression: shame and narcissistic vulnerability. Child Abuse \& Neglect, 51, 276-283. https://doi.org/10.1016/j.chiabu.2015.09.012

Kranz, D., Busch, H., \& Niepel, C. (2018). Desires and intentions for fatherhood: a comparison of childless gay and heterosexual men in Germany. Journal of Family Psychology, 32(8), 995-1004. http://dx.doi.org/10.1037/fam0000439

Lamb, M. E. (2010). The role of the father in child development (5th ed.). Hoboken: Wiley.

Lamb, M. E. (2000). The history of research on father involvement: an overview. Marriage \& Family Review, 20, 23-42. https://doi.org/10.1300/J002v29n02_03

Lei $n^{\circ}$ 8.069, de 13 de julho de 1990. (1990). Dispõe sobre o Estatuto da Criança e do Adolescente e dá outras providências. Brasília, DF: Presidência da República.

Lei $n^{\circ} 11.340$, de 7 de agosto de 2006. (2006). Cria mecanismos para coibir a violência doméstica e familiar contra a mulher, nos termos do $\S 8^{\circ}$ do art. 226 da Constituição Federal, da Convenção sobre a Eliminação de Todas as Formas de Discriminação contra as Mulheres e da Convenção Interamericana para Prevenir, Punir e Erradicar a Violência contra a Mulher; dispõe sobre a criação dos Juizados de Violência Doméstica e Familiar contra a Mulher; altera o Código de Processo Penal, o Código Penal e a Lei de Execução Penal; e dá outras providências. Brasília, DF: Presidência da República.

Lei $n^{\circ}$ 13.010, de 26 de junho de 2014. (2014). Altera a Lei no 8.069, de 13 de julho de 1990 (Estatuto da Criança e do Adolescente), para estabelecer o direito da criança e do adolescente de serem educados e cuidados sem o uso de castigos físicos ou de tratamento cruel ou degradante, e altera a Lei no 9.394, de 20 de dezembro de 1996. Brasília, DF: Presidência da República.

Lisboa, C. M. (2005). Comportamento agressivo e vitimização nas relações de amizade de crianças em idade escolar: fatores de risco e proteção. Tese de doutorado, Universidade Federal do Rio Grande do Sul, Porto Alegre, RS, Brasil.

Madalena, M., Carvalho, L. F., \& Falcke, D. (2018). Violência conjugal: o poder preditivo das experiências na família de origem e das características patológicas da personalidade. Trends in Psychology, 26(1), 75-91. https://dx.doi.org/10.9788/tp2018.1-04pt

Madureira, AB., Raimondo, M. L., Ferraz, M. I. R., Marcovicz, G. V., Labronici, L. M., \& Mantovani, M. F. (2014). Profile of men who commit violence against women who are arrested in delicto flagrante: contributions to confronting the phenomenon. Escola Anna Nery, 18(4), 600-606. https://dx.doi.org/10.5935/1414-8145.20140085

Maia, J. M. D., \& Williams, L. C. A. (2005). Fatores de risco e fatores de proteção ao desenvolvimento infantil: uma revisão da área. Temas em Psicologia, 13(2), 91-103. http://pepsic.bvsalud.org/scielo. php?script=sci_arttext\&pid=S1413-389X2005000200002\&lng=pt\&tlng=pt

Medrado, B., Lyra, J., Azevedo, M., \& Brasilino, J. (2010). Homens e masculinidades: práticas de intimidade e políticas públicas. Recife: Instituto Papai. 
Metz, C., \& Razon, L. (2015). Violences conjugales et transmission transgénérationnelle: que devient l'enfant témoin?. L'Évolution Psychiatrique, 80(3), 515-523. https://doi.org/10.1016/j.evopsy.2014.11.001

Minayo, M. C. S. (2013). Violência e educação: impactos e tendências. Revista Pedagógica, 15(31), 249-264.

Moreira, L. E., \& Toneli, M. J. F. (2013). Paternidade responsável: problematizando a responsabilização paterna. Psicologia \& Sociedade, 25(2), 388-398.

Muzio, P. A. (1997). Paternidade (ser pai): para que serve? In Silveira, P. Exercício da paternidade (pp.165-174). Porto Alegre: Artes Médicas.

Neigh, G. N., Ritschel, L. A., \& Nemeroff, C. B. (2010). Biological consequences and transgenerational impact of violence and abuse: understanding the risks associated with early life stress. Psychiatric Times, 27(11), 49.

Nolasco, S. (1993). O mito da masculinidade. Rio de Janeiro: Rocco.

Oliveira, K. L. C., \& Gomes, R. (2011). Homens e violência conjugal: uma análise de estudos brasileiros. Ciência \& Saúde Coletiva, 16, 2401-2413.

Olweus, D. (1993). Bullying at school: what we know and what we can do. Oxford: Blackwell.

Organização Mundial da Saúde. (2002). Relatório mundial sobre violência e saúde. Genebra: OMS.

Pacheco, J. T. B., Irigaray, T. Q., Werlang, B., Nunes, M. L. T., \& Argimon, I. I. L. (2014). Childhood maltreatment and psychological adjustment: a systematic review. Psicologia: Reflexão e Crítica, 27(4), 815-824. https://dx.doi.org/10.1590/1678-7153.201427422

Pasian, M., Bazon, M. R., Pasian, S., \& Lacharité, C. (2015). Negligência infantil a partir do Child Neglect Index aplicado no Brasil. Psicologia: Reflexão e Crítica, 28(1), 106-115.

Patrian, A. C. A, Rios, K. S. A., \&Williams, L. C. A. (2013). Validade de critério do inventário de potencial para abuso infantil (CAP). Paidéia, 23(54), 43-51. https://dx.doi.org/10.1590/1982-43272354201306

Petrucci, G. W., Borsa, J. C., \& Koller, S. H. (2016). A família e a escola no desenvolvimento socioemocional na infância. Trends in Psychology, 24(2), 391-402. http://dx.doi.org/10.9788/TP2016.2-01Pt

Poletto, M., \& Koller, S.H. (2008). Contextos ecológicos: promotores de resiliência, fatores de risco e de proteção. Estudos de Psicologia, 25(3), 405-416. https://dx.doi.org/10.1590/S0103-166X2008000300009

Poletto, M., Koller, S.H., \& Dell'Aglio, D. D. (2009). Eventos estressores em crianças e adolescentes em situação de vulnerabilidade social de Porto Alegre. Ciência \& Saúde Coletiva, 14(2), 455-466. https://dx.doi.org/10.1590/ S1413-81232009000200014

Prado, J. C., \& Abrão, J. L. F. (2014). Paternidade: um estudo sobre pesquisas desenvolvidas no contexto brasileiro. Colloquium Humanarum, 11(1), 94-112. https://dx.doi.org/10.5747/ch.2014.v11.n1.h152

Prodócimo, E., Farenzena, R. C., Costa, R. R., Silva, R. G. C., \& Mattosinho, P.V. B. (2013). Os adolescentes brasileiros e a violência entre pares na escola: o fenômeno visto de dentro para fora. Interacções, 9(25), 202-225.

Protogerou, C., \& Flisher, A. (2012). Bullying in schools. In: A. van Niekerk, S. Suffla, M. Seedat (Eds.). Crime, violence and injury in South Africa: $21^{\text {th }}$ century solutions for child safety. Tygerberg: MRC.

Razera, J. Cenci, C. M. B., \& Falcke, D. (2014). Violência doméstica e transgeracionalidade: um estudo de caso. Revista de Psicologia da IMED, 6(1), 47-51. https://doi.org/10.18256/2175-5027/psico-imed.v6n1p47-51

Riquelme, E., \& Munita, F. (2017). Mediated reading of children's literature as paradigmatic scenario to develop emotional competence. Psicologia: Teoria e Pesquisa, 33, e33315. https://dx.doi.org/10.1590/0102.3772e33315

Scarborough, A. A., Lloyd, E. C., \& Barth, R. P. (2009). Maltreated infants and toddlers: predictors of developmental delay. Journal of Developmental \& Behavioral Pediatrics, 30(6), 489-498.

Silva, A. C. L. G., Coelho, E. B. S., \& Moretti-Pires, R. O. (2014). What we know about men who commit violence against their intimate partners: a systematic review. Revista Panamericana de Salud Publica, 35(4), 278+. http:// link-galegroup.ez4l.periodicos.capes.gov.br/apps/doc/A373887137/AONEu=capes\&sid=AONE\&xid=e9f30207

Silva, C, Gomes, V. O., Mota, M. S., Gomes, G. C., \& Amarijo, C. L. (2015). Violência contra a mulher: agressores usuários de drogas ilícitas. Cuidado É Fundamental, 7(2), 2494-2504.

Silva, C. E., Oliveira, R. V., Bandeira, D. R., \& Souza, D. O. (2012). Violence among peers: a case study in a public school in Esteio/RS - Brazil. Psicologia Escolar e Educacional, 16(1), 83-93. https://dx.doi.org/10.1590/ S1413-85572012000100009 
Silva, B. T., Silva, M. R. S., \& Bueno, M. E. N. (2014). Eventos intra e extrafamiliar significativos no processo de construção da paternidade. Escola Anna Nery Revista de Enfermagem, 18(4), 710-715. https://dx.doi.org/10.5935/1414-8145.20140101

Sluzki, C. E. (2010). Personal social networks and health: conceptual and clinical implications of their reciprocal impact. Family Systems and Health, 28(1), 1-18.

Smith, P., Depra, P., \& Rigby, K. (2004). Bullying in schools: how successful can interventions be?. Cambridge: Cambridge University Press.

Souza, A. P. L., Lauda, B. V., \& Koller, S. H. (2014). Opiniões e vivências de adolescentes acerca dos direitos ao respeito e privacidade e à proteção contra a violência física no âmbito familiar. Psicologia \& Sociedade, 26(2), 397-409.

Souza, E. R., Melo, A. N., Silva, J. G., Franco, S. A., Alazraqui, M., \& González-Pérez, G. J. (2012). Estudo multicêntrico da mortalidade por homicídios em países da América Latina. Ciência \& Saúde Coletiva, 17(12), 3183-3193. https://dx.doi.org/10.1590/S1413-81232012001200004

Staudt, A. C. P., \&Wagner, A. (2008). Paternidade em tempos de mudança. Psicologia: Teoria e Prática, 10(1), 174-185.

Sutter, C., \& Bucher-Maluschke, J. S. N. F. (2008). Pais que cuidam dos filhos: a vivência masculina na paternidade participativa. PSICO, 39(1), 74-82.

Teixeira-Filho, F. S., Rondini, C. A., \& Silva, J. M., Araújo, M. V. (2013). Tipos e consequências da violência sexual sofrida por estudantes do interior paulista na infância e/ou adolescência. Psicologia \& Sociedade, 25(1), 90-102. https://dx.doi.org/10.1590/S0102-71822013000100011

Wang, M., Wang, X., \& Liu, L. (2016). Paternal and maternal psychological and physical aggression and children's anxiety in China. Child Abuse \& Neglect, 51, 12-20. https:// doi.org/10.1016/j.chiabu.2015.11.018

World Health Organization, \& International Society for Prevention of Child Abuse and Neglect. (2009). Preventing child maltreatment: a guide to taking action and generating evidence. Geneva: WHO.

Yoder, J. R., Brisson, D., \& Lopez, A. (2016). Moving beyond fatherhood involvement: the association between father-child relationship quality and youth delinquency trajectories. Family Relations, 65(3), 462-476. https://doi.org/10.1111/fare.12197

\section{Priscila Jandrey Brasco}

Mestra em Psicologia e Saúde pela Universidade Federal de Ciências da Saúde de Porto Alegre, Porto Alegre - RS. Brasil. E-mail: priscilajbrasco@gmail.com

(1) https://orcid.org/0000-0003-0311-6642

\section{Clarissa De Antoni}

Docente do Programa de Pós Graduação em Psicologia e Saúde da Universidade Federal de Ciências da Saúde de Porto Alegre, Porto Alegre - RS. Brasil.

E-mail: clarissadeantoni@gmail.com

(1) https://orcid.org/0000-0003-4521-9148

Endereço para envio de correspondência:

Universidade Federal de Ciências da Saúde de Porto Alegre, Departamento de Psicologia. Rua Sarmento Leite, 245, sala 207, Centro Histórico, CEP: 90050-170, Porto Alegre - RS. Brasil.

Recebido 27/12/2018

Aceito 05/03/2020

Received 12/27/2018

Approved 03/05/2020

Recibido 27/12/2018

Aceptado 05/03/2020 
Psicologia: Ciência e Profissão 2020 v. 40, e218119, 1-16.

Como citar: Brasco, P. J., \& De Antoni, C. (2020). Violências Intrafamiliares Experienciadas na Infância em Homens Autores de Violência Conjugal. Psicologia: Ciência e Profissão, 40, 1-16. https://doi.org/10.1590/1982-3703003218119

How to cite: Brasco, P. J., \& De Antoni, C. (2020). Intrafamily Violence Experienced in Childhood of Men Authors of Intimate Partner Violence. Psicologia: Ciência e Profissão, 40, 1-16. https://doi.org/10.1590/1982-3703003218119

Cómo citar: Brasco, P. J., \& De Antoni, C. (2020).Violencia Intrafamiliar Experimentada en la Infancia por Hombres Autores de Violencia de Parejas. Psicologia: Ciência e Profissão, 40, 1-16. https://doi.org/10.1590/1982-3703003218119 